\title{
Water-Energy-Food Nexus Approach: Motivations, Challenges and Opportunities in Algeria
}

\author{
Nadjib DROUICHE, Salaheddine AOUDJ \\ Centre de Recherche en technologie des Semi-conducteurs pour l'Energétique (CRTSE). 2, Bd Frantz Fanon BP140, \\ Alger -7 merveilles, 16038, Algeria
}

\begin{abstract}
water energy food nexus (WEF) originates in the interconnections between the three resources as they are significant input for the production of each other and have major impacts on each other when mobilized and or utilized, conditioning the requirement of intertwined management and sustainability for all (fig.1). Therefore, the solutions for water, energy and food security problems are beyond the single-minded technical approach that mainly focuses on technology. The Nexus approach integrates management and governance across sectors and scales, with the aim of achieving water security, sustainable energy and food security to reduce hunger and poverty, and improve livelihoods. It is about governance within the three sectors and other relevant ones. It entails collaboration and coordination amongst the relevant sectors through the adoption of a holistic vision and integrated planning manners. This allows decision makers to develop the right strategies and plans that contribute to the achievement of sustainable development, maximize the benefits of the investments and ensure resources sustainability.
\end{abstract}

Keywords: Algeria, Food, water, energy

\section{Introduction}

In Algeria, the water natural scarcity together with drought due to climate changes as well as increasing the pollution are identified as the most critical drivers destabilizing the existing balance between the water demand and supply, which will get worse over the few next years, perhaps more than any other region in the world. Therefore, defining and quantifying interconnectivity between water, energy, and food, on the basis of which they can be used for policy and knowledge-sharing system for planning; become a must.

In Algeria there are about 40 million people who need water, food, and energy. While there are many impediments and challenges towards NEXUS approach, these can be overcome by comprehensive planning, risk assessment and policy implementation. Undoubtedly, the holistic Nexus approach in Algeria will empower a hub for knowledge and technology exchange and for innovating, adding value to economy by providing employment opportunities, reducing environmental impacts, adapting and benchmarking solutions.

* Corresponding author

E-mail: nadjibdrouiche@yahoo.fr

(C) 2015 International Association for Sharing Knowledge and Sustainability

DOI: $10.5383 /$ ijtee.10.01.002
Replication of successful projects implemented in the north side of the Mediterranean Sea is beneficial but the system should be adjusted to meet the local conditions. Additionally, a comprehensive and long term strategy that requires extensive planning and implementation phases is vital for reaching nexus approach implementation.

\section{Water Energy Nexus}

For humans to be able to utilize the available water resources, energy from some sources is needed to extract groundwater, feeding desalination plants, producing freshwater, pumping, conveying, and distributing freshwater, collecting wastewater, processing and treating the substance at every phase of its extraction, distribution and use. Water cycle demands at least $15 \%$ of national electricity consumption, and is continuously increasing while water is used in the generation of most forms of traditional turbine produced electricity, hydroelectric schemes and through desalination (Co-generation of Power Desalting Plants), in addition to many other applications. Sometimes water is a direct input to the energy generation process: cooling, hydropower, geothermal, exploration and 
refining. Much more often it plays a role at various intermediate phases of electricity generation (cooling, etc) [1].

The water shortage of fresh water resources in Algeria triggered the use of desalination, mainly based on Reverse Osmosis (RO). The implemented desalination plants increased the overall energy consumption. As energy production is based on fossil-fuels, a finite source, it is obvious that promoting renewable energies to power desalination plants is needed.

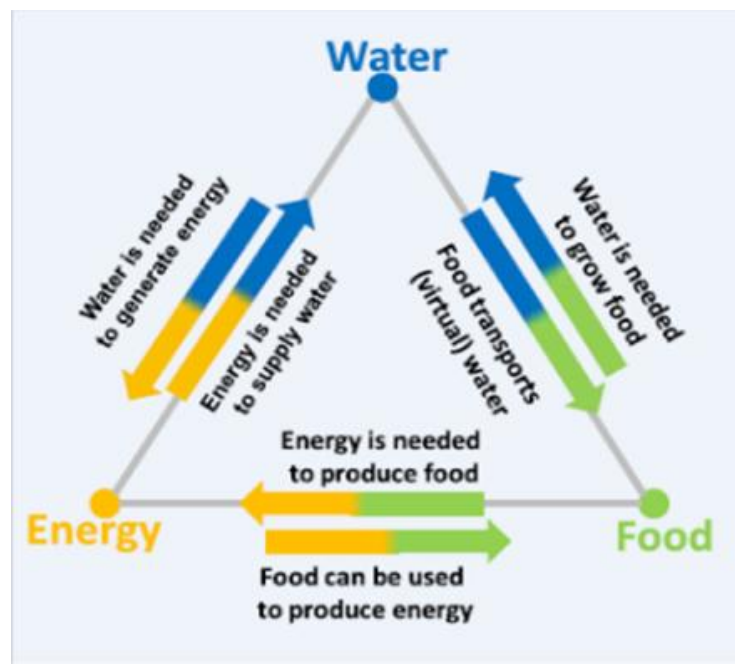

Figure 1: The Water-Energy-Food Nexus (UNU, 2013)

Special attention should be paid to renewable safe energy sources, of which the most important is solar, which can have enormous potential as Algeria holds one of the highest solar potentials in the world which is estimated at 13.9 TWh per year.

\subsection{Renewable Energy Policy}

The energy system in Algeria is still relying mainly on natural gas and fossil fuel resources. Amongst others, greenhouse emissions from the provision of energy services contribute significantly to the increase in atmospheric greenhouse gas concentration. In order to overcome this situation, energy system transition is necessary to mitigate climate change and solve additional environment related challenges. In this manner planned energy scenarios are necessary to enable well-founded political decisions. The planed renewable energy contributions in Algeria are summarized below:

- Installation of a total power capacity of 110 MW by 2013;

- Installed power capacity to reach $650 \mathrm{MW}$ by 2015 ;
- Installed power capacity to reach about 2600 MW by 2020 and a possibility of export of 2000 MW;

- An additional capacity of about $12000 \mathrm{MW}$ is expected to be installed by 2030 and a possibility of export up to $10000 \mathrm{MW}$.

Renewable energy applications in Algeria were implemented over the past two decades, and several photovoltaic were installed on a small scale in isolated areas for different uses, specifically, rural electrification, telecommunications and water pumping. However, these renewable energy applications have not attracted the attention of the state actors in the energy sector, until the last ten years. Specifically, Algeria aspires to ensure its energy transition and to provide a sustainable answer to energy supply and management issues by carrying out a national renewable energy plan. This plan is based on expanding the use of renewable resources and energy efficiency program and aims toward renewable energies as the main stream of the national energy supply system with a target contribution of 22,000 MW of the electricity demand by 2030 . This program is in line with all the projects that the Algerian Government is implementing to improve its energy sector performance. The main features of the policy are:

- $\quad 99-09$ act of July $28^{\text {th }}, 1999$, related to energy efficiency;

- 02-01 act of February $5^{\text {th }}, 2002$ related to electricity and gas distribution pipeline;

- 04-09 act of August, $14^{\text {th }} 2004$, related to the promotion of renewable in the context of sustainable renewable energies and sustainable development;

- 04-92 decree of March 25 $5^{\text {th }}, 2004$ that defined the costs of diversification of electricity generated by renewable energies;

- $\quad 05-495$ decree of December $26^{\text {th }}, 2005$ related to energy efficiency.

The renewable energies are expected to be an important field of cooperation between Algeria and neighbourhood countries through investment projects, technology transfer initiatives, capacity building and knowledge transfer.

Due to high potential of renewable energy sources in Algeria and its location near the energy market in Europe, it is possible to plan in the future to generate electricity from renewable sources in Algerian southern regions and to deliver it to Europe. Figure 1 shows a map for future electricity supply scenario from renewable sources (Fig. 1; Dib et al.,). 


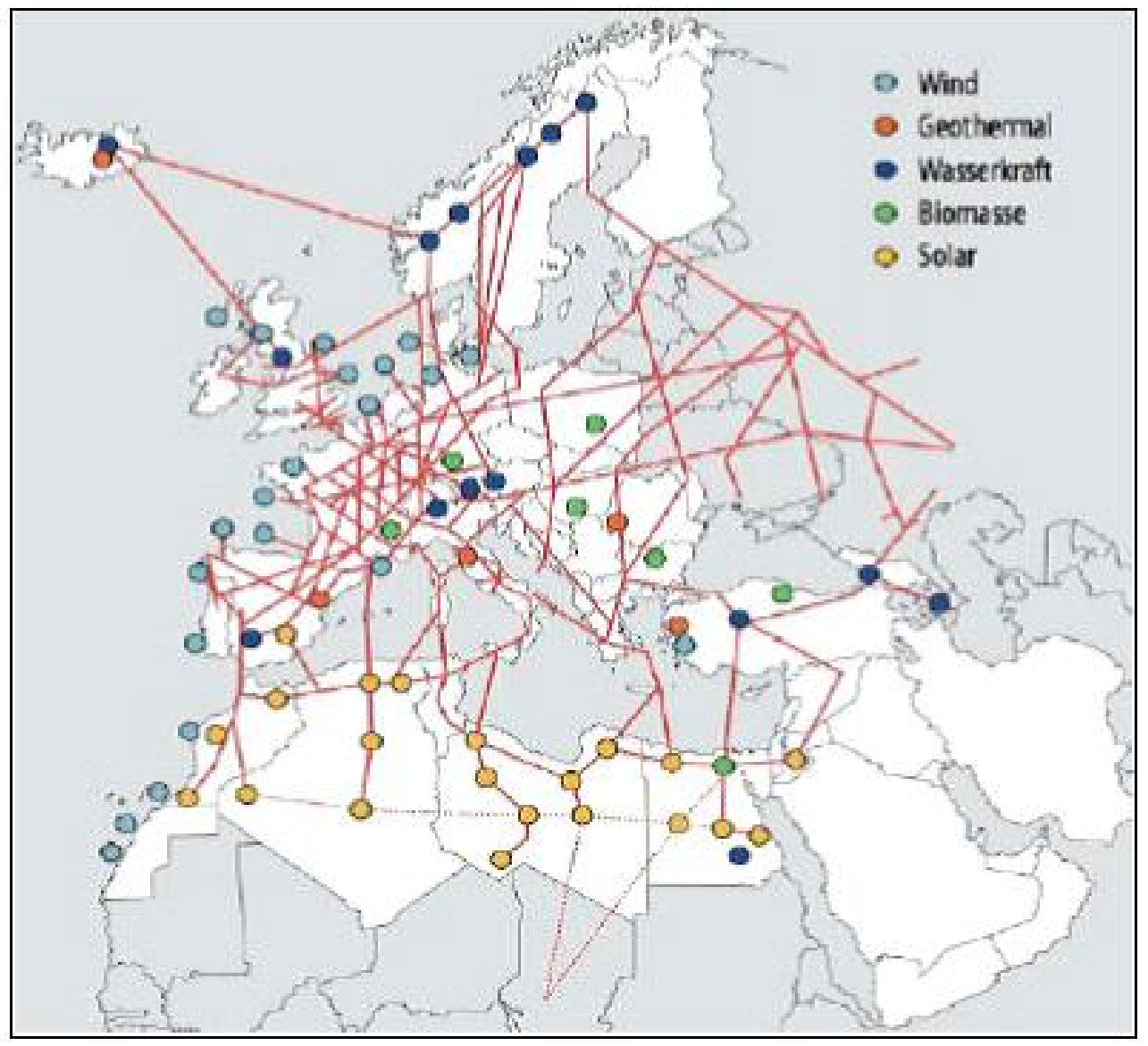

Figure 2: Map for future electricity supply scenario from renewable sources

It is clear that renewable energy technologies have great potential for contributing to a sustainable energy mix in Algeria. However, more action is needed and should include:

- Integrating renewable energy policies into national energy policies with defined and targeted contributions.

- Strengthening relevant national institutions.

- Encouraging renewable energy technology transfer and supporting local industries seeking to develop or use renewable energy technologies.

- Intensifying capacity building and public awareness programs.

- Initiating new financial mechanisms for supporting renewable energy adopting, particularly in remote areas.

- Policies must be aimed at localizing the renewable energy supply chain and strengthening technological capabilities at various levels.
- Innovation capabilities are needed to increase local companies' participation in more technology intensive activities in the value chain

- There is a need for a national technology strategy to direct research activities and funds towards research in this field.

- Government should and must design incentive packages to promote private sector investments in renewable energy and other off-grid generation

- Government must also provide requisite support for research and development in emerging technologies.

One of the strategies in reforming subsidies on fossil fuels could be stopping (or reducing) the large amount of government subsidies given to natural gas and oil. Not only would this improve the finances of Algeria budget, but it would also make renewable energy a more affordable source of electricity. 


\section{Water Food Nexus}

Water-Energy and Food in Algeria are strongly interlinked and highly interdependent. Algeria is facing a water scarcity challenge, where agriculture is its predominant consumer. Water withdrawn for irrigation, livestock and aquaculture purposes accounts for approximately almost $4,000 \mathrm{MCM} / \mathrm{yr}$, or $64 \%$ of global water withdrawals today [4], and is forecast to grow at a compound annual rate of $6.8 \%$.
In addition to the increase in water scarcity, the agricultural sector faces an enormous challenge of producing almost $50 \%$ more food by 2030 and doubling production by 2050 .

Study conducted by the World Bank has shown that more than half of the food calories consumed in Algeria is imported and would increase dramatically over the next decades. An older study in the mid-1990s has shown that the food import of Algeria was equivalent to $87 \%$ billion $\mathrm{m}^{3}$ of virtual water.

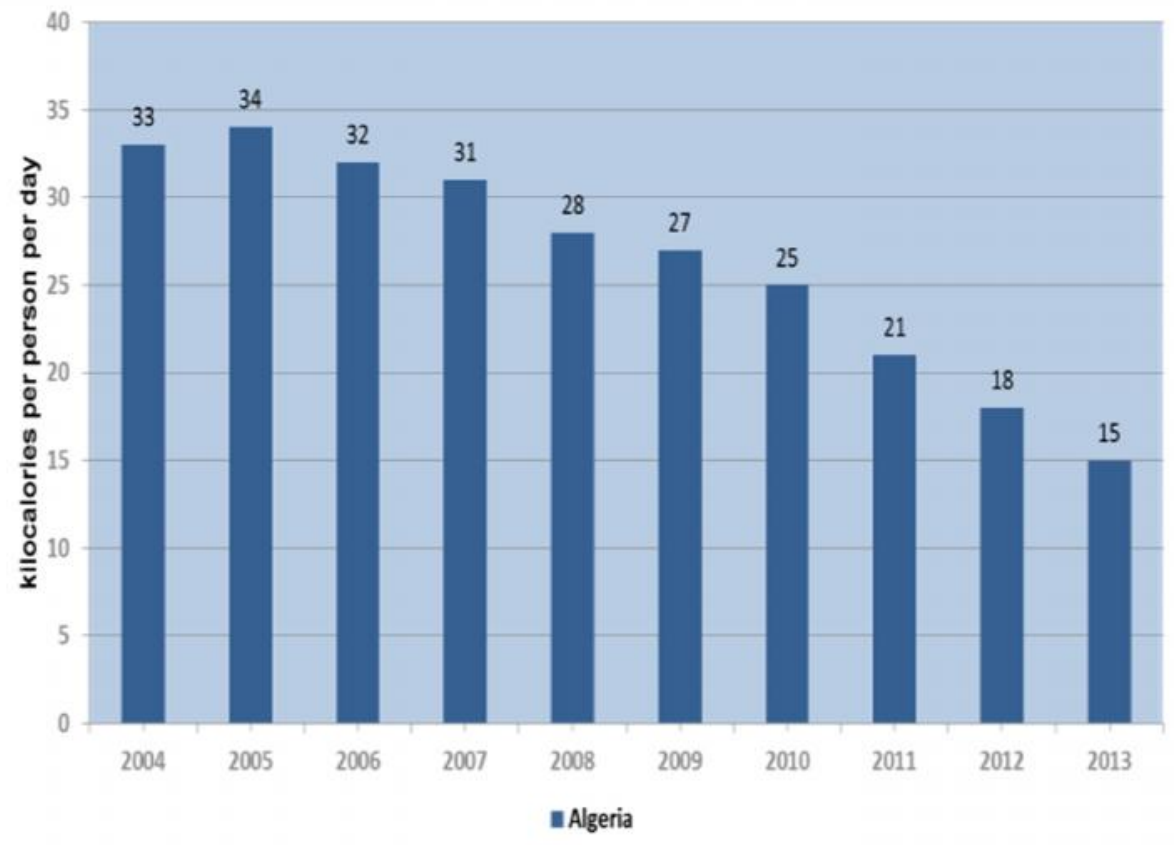

Figure 3: Depth of the food deficit

\section{Policy Recommendations}

Based on the landscape analysis of the water, energy and food security nexus in Algeria the following recommendations could allow decision makers to develop the right strategies and plans that contribute to the achievement of sustainable development of each of these three sectors:

1) The development of a national strategy for planning and implementing projects utilizing the nexus approach to promote coordination and collaboration across sectors, based on national information systems and a high level ministerial coordination.

2) Adopting a nexus knowledge platform to enable information sharing.

3) The implementation of a national Nexus steering committee comprised of policymakers, researchers, and civil society organizations to join management strategy to promote projects in these three sectors.

4) Promote energy efficiency and the improved wastewater management.

\section{Conclusions}

The strong interaction between energy and water will demand an equally strong policy. Moving forward, public policy should be tailored to account for water use as a metric related to overall sustainability of a particular energy system, or an energy resource roadmap. Similarly, better data on current water use, in all sectors of the economy, as well as energy, is necessary in order to better educate the public about their use of water and allow stake holders to make better informed decisions regarding this resource. The nexus approach presents an opportunity for Algeria to make strides in three sectors without comprising its natural or social environment. Effective governance in the water, energy and food security sectors and the use of holistic approaches will set the stage for Algeria to continue making strides towards economic growth. The nexus must prevail at all levels, based on inclusiveness for all sectors of the economy including: policy makers, stakeholders, academic, civil society and private sector. 


\section{References}

[1] Waleed K. Al-Zubari, Water, energy, and food Nexus in the Arab region, 2014

[2] Khatib, H. 2010. The Water and Energy Nexus in the Arab Region. League ofArab States, Cairo.

[3] N Drouiche, N Ghaffour, MW Naceur, H Mahmoudi, $\mathrm{T}$ Ouslimane.Reasons for the fast growing seawater desalination capacity in Algeria. Water resources management 25 (11)(2011), 2743-2754

[4] http://www.ecomena.org/tag/algeria/

[5] World Bank (2009). Water Resources: Managing a Scarce, Shared Resource. http://siteresources.worldbank.org/IDA/Resources/I DA-Water_Resources.pdf

[6] http://www.rknow.net/index.php/en/themesen/project-database/item/the-water-energy-foodsecurity-nexus-opportunities-for-sustainabledevelopment-and-effective-environmentalgovernance

[7] http://www.businessmonitor.com/; www.aprue.org.dz; www.mem-algeria.org
[8] http://www.businessmonitor.com/

Y. Himri, S. Himri, A. Boudghene Stambouli, "Wind power resources in the south-western region of Algeria”, Renewable and Sustainable Energy Reviews, vol. 14, pp.554-556, 2012.

[9] http://www.businessmonitor.com/

[10] A. B. Stambouli, Z. Khiat, S. Flazi, Y. Kitamura, "A review on the renewable energy development in Algeria: Current perspective, energy scenario and sustainability issues", Renewable and Sustainable Energy Reviews, vol. 16, pp.4445-4460, 2012.

[11] A. B. Stambouli, "Algerian renewable energy assessment: the challenge of sustainability", Energy Policy, Vol. 39 (8), pp.4507-4519, 2011.

[12] S. Menani, "Algeria renewable energy program: outlook and applications", Energy Week Conference, Vaasa, Finland, 2012.

[13] Djalel DIB et al., International Journal Of Renewable Energy Research Vol.2, No.3, 2012. 